\title{
Prosody of focus in statements of the Altai language
}

Elena Shestera, Nikolay Urtegeshev, Iraida Selutina, Anton Shamrin

Laboratory of Phonetics, Siberian Branch of Russian Academy of Science, Russia https://doi.org/10.36505/ExLing-2020/11/0046/000461

\begin{abstract}
The prosody of verbal word forms in the narrative utterances of the Altai language is under consideration in the article. In this work, in addition to the acoustic analysis in the Praat program, we took into account the subjective perception of native speakers. In the simple statements the intonation declines on the predicate when realizing the topic of the utterance. The focus of the utterance may be expressed by pitch and intensity peak.
\end{abstract}

Keywords: Altai language, intonation, prosody, narrative statement, topic, focus

\section{Introduction}

Intonation serves as a means of forming the communicative type of a sentence and syntactic relations between parts of a complex sentence and performs a delimitative and text-forming function. Since the expression of syntactic relations and the communicative type of an utterance is one of the functions of intonation, let us consider the relationship between intonation and information structure expressed in the prosody of verbal word forms of the Altai language.

The information structure of an utterance is expressed by the topic and focus. The topic corresponds to the logical subject of the proposition, while the focus is rather new or contrastive information that was stated or asked about. The focus contains new information and has the highest degree of communicative dynamism, but the completeness of information, or givenness, is created by a dynamic combination of the focus and topic (Dufter, Gabriel 2016). We could assume that the intonation contour of the focus differs from that of the topic, speech production being dependent on the sentence information structure is quite predictable, and it may be characterized as 'the topic intonation' or 'the focus intonation'.

An Altai utterance having the fixed word order S-O-P, in contrast to the Russian one, suggests the presence of certain intonation for expressing the topic and different intonation for the focus of the utterance. The material under investigation is a simple two-part (and simple one in complex sentences) statement with the topic and focus, where the subject is topic, and the predicate or object is focus. For each sentence (depending on the context), it is decided separately whether the predicate (which is expressed by a verbal word form and is a compound or nominal verb) represents the topic or focus of the utterance.

ExLing 2020: Proceedings of 11 th International Conference of Experimental Linguistics, 12-14 October 2020, Athens, Greece 


\section{Material and methods}

The research material was audio recordings of folk works of Altaians, i.e. AltaiKizhi (Monuments of folklore... 2002, 2011). Audio recordings of the Altai folk tale and non-folktale prose fragments produced by four native speakers were listened to. Then utterances were selected for analysis. Our preference was given to simple uncomplicated sentences, but complicated sentences with homogeneous terms, and complex sentences were also under consideration.

Using an audio converter, all audio files were converted from WMA to WAV format. In the Audacity program, the sound signals were cut into separate utterances of the declarative communicative type. The resulting working files were annotated in the Praat program at several levels, but the material - 100 simple statements - was analyzed only at the syllabic sublevel.

\section{Results}

Consider some sample phrases pronounced by the native Altaian speakers.
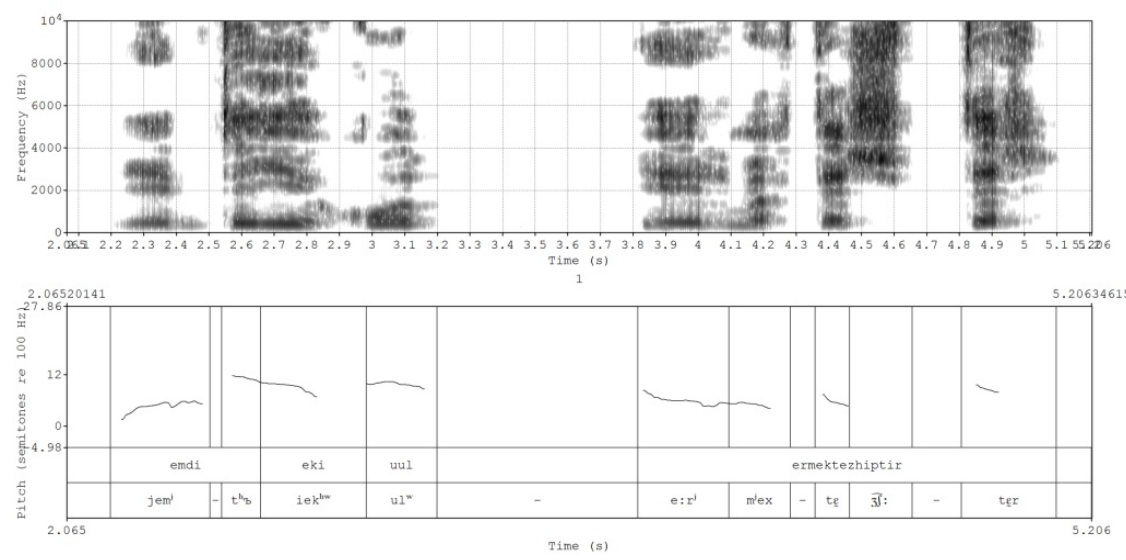

Figure 1. Emdi eki unl ermektęhiptir. - 'Here two brothers are speaking.'

The sentence in Figure 1 is simple, uncomplicated, between the group of the subject (which includes the adverbial modifier, the subject and the attribute) and the predicate we find a physical pause. The first intonation phrase - the group of the subject emdi eki uul - has an ascending-descending pitch. The maximum of F0 is on the second syllable of the adverbial emdi 'here'. On the verb, the pitch is generally lowered. An unexpectedly high F0 value appears on the final syllable of the predicate - perhaps it occurs as a result of drawing the listener's attention to what the narration will be about further, i.e., the predicate is the focus in the sentence. 

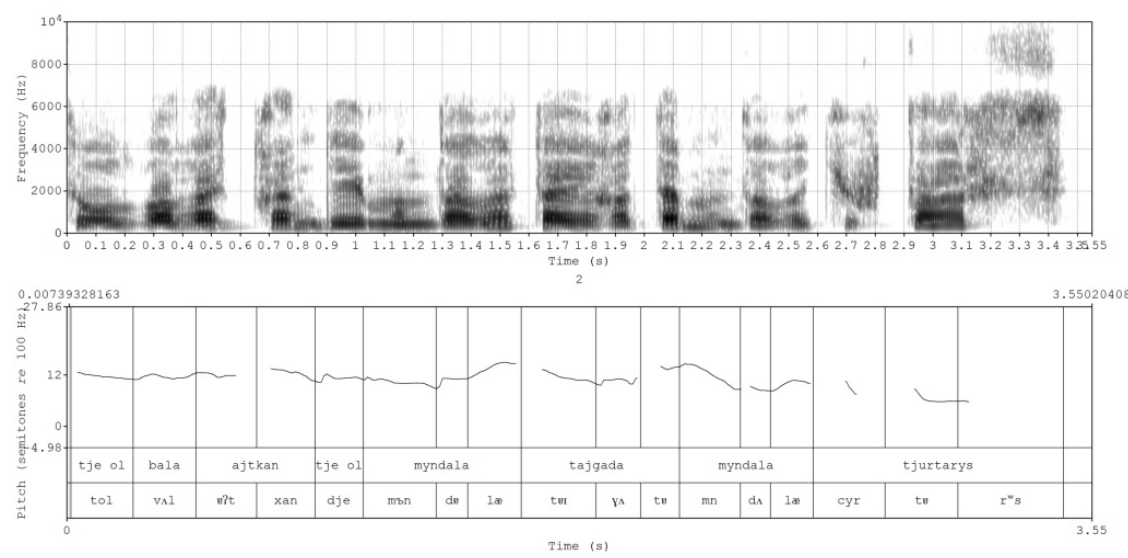

Figure 2. Tje ol bala ajtkan, tje ol myndala tajgada, myndala tjurtarys. - 'But this girl said, but here in taiga, here will we live.'

The sentence in Figure 2 begins with the conjunction tje 'but'. In the sentence, there is a lexical repetition of the adverbial myndala 'here'. The intonation contour is not stable: there are two F0 maxima occurred in both cases of the adverbial myndala 'here'. In the first case, the pitch increases, then decreases; on the repeated word myndala, the pitch decreases from high F0 value to low one in the utterance, reaching the lowest $\mathrm{F} 0$ value on the predicate in the final position of the sentence. Thus, the focus can be expressed not only by nuclear accent, or raising pitch, but also by pitch movements, i.e., from relatively high to minimal ones. This finding is consistent with the idea of $\mathrm{R}$. Ladd that pitch increases are functional and may convey focus, and they are significant not only as individual components of intonation (out of context), but as a part of the global 'rise-fall' contour of an utterance (Ladd 1995: 117).
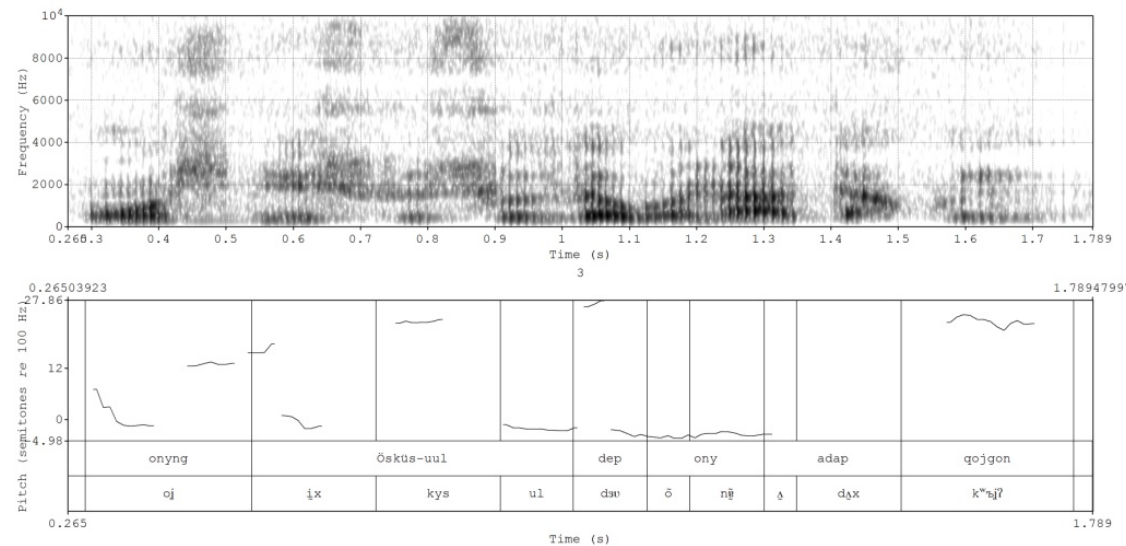

Figure 3. Onyng uchun Ösküs-uul dep ony adap qojgon. - 'Thus Ösküüs-lad was named like that'. 
Here in this sentence in Figure 3, the compound conjunction onyng uchun 'thus' is found, and together with the verbal word dep 'having said' they may be attributed to the metatextual linkers. Being emphasized with the maximum pitch value, these contextual words realize the so called contrastive focus of this utterance; for further information the reader is referred to (Dufter, Gabriel 2016: 6). On the verb $a d a=$ 'to give name' we can observe declining F0 contour, which has the minimum pitch value at the end of the utterance. It is interesting that not only the F0 maximum but intensity peak is realized on the verbal word dep 'having said' as well. This metatextual linker originating from participial form of the verb de = 'to say' in folk texts often performs the function of strengthening declarativeness (of the statements) (Tybykova 1991: 175).

\section{Conclusion}

Thus, in the Altai language, the rise-fall intonation contour is mainly observed in declarative utterances. In a simple statement characterized by the standard for Altai word order S-O-P, the intonation declines on the predicate when realizing the topic of the utterance. The focus of the utterance may be expressed by pitch and $\backslash$ or intensity peak, or pitch movement from high value to lower one on the syllable of the emphasized word of the utterance.

\section{Acknowledgements}

This research is carried out within the framework of the project of the Institute of Philology of the Siberian Branch of the Russian Academy of Sciences «Cultural universals of verbal traditions of the peoples of Siberia and the Far East: folklore, literature, language» supported by a grant from the Government of the Russian Federation for the promotion of research conducted under the guidance of leading scientists, contract № 075-15-2019-1884.

\section{References}

Dufter A., Gabriel Ch. 2016. Information structure, prosody, and word order. In Fischer, S., Gabriel, Ch. (Eds.), Manual of Grammatical Interfaces in Romance 10. Berlin: De Gruyter.

Ladd R. 1995. 'Linear' and 'Overlay' descriptions: An autosegmental-metrical middle way. Proceedings of XIIIth International Congress of Phonetic Sciences, 116-123. Stockholm, Sweden.

Monuments of Folklore of the Peoples of Siberia and the Far East. Vol. 21: The Altai folktales. Novosibirsk, Nauka, 2002, 455 p. (in Russian).

Monuments of Folklore of the Peoples of Siberia and the Far East. Vol. 30: The Altai non-folktale prose. Novosibirsk, Nauka, 2011, 576 p.(in Russian).

Tybykova A. T. Research on the Syntax of the Altai Language: a Simple Sentence. Novosibirsk, 1991, 174-178. (in Russian). 